\title{
Orman ekosisteminde toprak solucanlarının önemi ve popülasyonlarının örneklenmesinde kullanılan metotlar üzerine bir bakış
}

\author{
İbrahim TAVUÇ (Orcid: 0000-0002-5926-4532) ${ }^{1 *}$ \\ ${ }^{1}$ Süleyman Demirel Üniversitesi, Orman Fakültesi, ISPARTA \\ *Sorumlu yazar/Corresponding author: ibrahimtve@gmail.com, Geliş tarihi/Received: 29.03.2017, Kabul tarihi/Accepted: 05.06.2017
}

$\ddot{\mathbf{O} z}$

Toprağın fiziksel, kimyasal ve biyolojik özelliklerini farklı yönlerde olumlu olarak etkileyen ve ekosistem mühendisi olarak adlandırılan toprak solucanları orman ekosisteminin oluşumu, yapısı, işleyişi ve fonksiyonu üzerine önemli etkilere sahiptir. Ancak, 150 yıldan daha uzun süredir toprak solucanları ile çalışılmasına rağmen, toprak solucanlarının ekolojileri, taksonomileri ve temel özellikleri konusunda ciddi bir bilgi eksikliği vardır. Toprak solucanları hakkındaki bilgi eksikliğini giderebilmek için toprak solucanlarının yetişme ortamı ile ilişkileri, gösterge türlerin tespiti ve potansiyel dağılım modellemeleri konularında araştırmalara ihtiyaç vardır. Toprak solucanları ile ilgili bilgi eksikliğini gidermek için ilk olarak toprak solucanlarının topraktan zarar görmeden çıkarılmaları gerekmektedir. Derlemede toprak solucanı envanter çalışmalarında en çok kullanılan kazma ve elle ayırma, elektrikle çıkartma, formaldehit ile çıkartma, soğan ekstraktı ile çıkartma, hardal ile çıkartma, allyl isothiocyanate (AITC) ile çıkartma, potasyum permanganat ile çıkartma ve tuzakla yakalama metotlarına yer verilmiștir. Çalıșma, özellikle orman ekosistemlerinde gelecekte ülkemizde yapılacak olan toprak solucanı çalışmalarına 1şık tutmak ve yardımcı olmak amacıyla hazırlanmıştır.

Anahtar Kelimeler: Envanter, ekosistem, vejetasyon, toprak, toprak solucanı çıartma metotları .

\section{The importance of earthworms in forest ecosystem and a review on methods used for the sampling of their population}

\begin{abstract}
Affecting the physical, chemical and biological characteristics of soil positively, eartworms called ecosystem engineers have significant impact on the function, mechanism, structure and formation of forest ecosystem. Studies have been carried out on earthworms for over 150 years; hovewer, there is a serious lack of information related to their ecological, taxonomic and basic characteristics. It is, therefore, required to conduct studies on the habitat of earthworms, determination of indicator species, and potential distribution modelling. So as to learn more about them, the first thing to do is to remove earthworms to the surface without giving any harm. In this paper, the most commonly used methods such as digging and hand sorting method, formaldehyde extraction method, mustard extraction method, allyl isothiocyanate (AITC) extraction method, potassium permanganate extraction method, electrical device extraction method, and using traps were explained. The study aims to provide more information on earthworms and to shed light on the future works that will be carried out on forest ecosystems.
\end{abstract}

Keywords: Inventory, ecosystem, vegetation, soil, earthworm extraction methods.

To cite this article (Atıf): TAVUNÇ I., 2017. Orman ekosisteminde toprak solucanlarının önemi ve popülasyonlarının örneklenmesinde kullanılan metotlar üzerine bir bakış, Orman Genel Müdürlüğü Ormancılık Araştırma Dergisi, 1(4):22-29 DOI: https://doi.org/10.17568/ogmoad.302647

\section{Giriş}

Perm-Karbon devrinden önce bugünkü tüm kıtalar Pangea adı verilen tek bir kara parçası halindeydi. Dünyamız tek kara parçası halinden günümüzdeki kıtaların oluşumuna kadar geçen sürede birbirinden farklı özelliklere sahip olan dönemlerden geçmiştir (Taşdelen, 2012). Toprak solucanları, toprak içerisinde ve taşların altında yaşadıkları için bu dönemler boyunca mutasyona neden olabilecek olan etkilerden korunmuş ve ana kıta döneminden itibaren neredeyse hiç değişime uğramadan günümüze kadar gelmiştir (Misırlıoğlu, 2001).

Karasal ekosistemin çok önemli bir parçası olan bu canlılar halkalı solucanlar olarak bilinen Annelida şubesinin Oligochaeta sınıfına ait Lumbricidae familyası içinde yer alırlar (Mısırlığlu, 2011).

Toprak solucanları toprağın fiziksel, kimyasal ve biyolojik özelliklerini birbirinden farklı şekilde etkilemektedir (Zicsi ve ark., 2011). Toprak solucanları bu etkilerine ve topraktaki yaşam katmanlarına göre Epijeik, Endojeik ve Anesik türler olmak üzere 3 ekolojik gruba ayrılmaktadır (Mısırlıoğlu, 
2011). Dünya üzerinde 3.000 'den fazla solucan türü olduğu bilinmektedir (FIBL, 2014). Ülkemizde ise

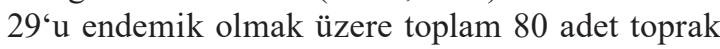
solucanı türü bulunmaktadır (Misırlığlu, 2017).

Toprak solucanları 1lıman ormanlarda, ekosistemin hem toprak altı, hem de toprak üstü canlı ve cansız bileşenlerini etkileyen en önemli omurgasız canlı grubudur (Szlavecz ve ark., 2013) ve toprak üzerine olan etkileri hafife alınmayacak kadar büyüktür (Staddon ve ark., 2003).

Beslenme, dışkılama ve toprak içerisinde galeri açma aktiviteleri ile toprağın fiziksel, kimyasal ve biyolojik özelliklerini önemli ölçüde etkileyerek besin ve enerji akışını etkilemektedirler (Çakır ve Makineci, 2011).

Toprak içerisinde açtıkları galeriler ile toprağın su geçirgenliğini, gözenekliliğini ve toprak havalanmasını artırarak doğal bir drenaj sistemi oluşturmakta, yüzey akıntısını ve erozyonu önlemektedir. Ayrıca bitki kökleri açılan bu galerilerin \%90'dan fazlasını kullanarak herhangi bir zorluk ile karşılaşmadan toprağın daha derin kısımlarına kolaylikla ilerleyebilmektedir (Steffen ve ark., 2013; FIBL, 2014).

Beslenme aktiviteleri ile toprak üstünde bulunan organik maddeleri açtıkları galerilere taşıyarak burada ayrıştırmaktadır. Bu ayrıştırma işlemi ile besin maddesi mineralizasyonunu sağlayarak hem orman topraklarının mineral ve karbon içeriğinin zenginleşmesini, hem de toprak horizonunun karıştırılması ile organik maddenin dağılımını sağlar (Steffen ve ark., 2013; Crumsey, 2014).

Dışkılama faaliyeti toprak solucanlarının en önemli faaliyetlerinden biridir. Çünkü solucan dışkılar1 topraktan daha yüksek $\mathrm{pH}$ değerine sahiptir ve bitkilerin gelişimi için gerekli olan çözülebilir karbon, polisakkaritler, potasyum, kalsiyum, magnezyum ve iz elementler içermektedir. Bu nedenle bitki gelişimini olumlu yönde etkilemektedir (Jouquet ve ark., 2008; Birkas ve ark., 2010). Bunun yanında toprak solucanları toprağın organik karbon döngüsünü hızlandırmaktadır (Valchovski, 2016).

Tüm bu olumlu etkilerine ek olarak, toprak solucanları toprağın kalitesini gösteren mükemmel biyoindikatörlerdir, bu nedenle toprak kalitesi izleme çalışmalarında sıklıkla kullanılmaktadırlar (Steffen ve ark., 2013).

Toprak solucanları 19. yüzyılda toprak zararlısı olarak düşünülmekte iken (FIBL, 2014), günümüzde toprağın fiziksel, kimyasal ve biyolojik özelliklerine olan etkilerinin anlaşılması nedeniyle ekosistem mühendisleri olarak adlandırılmaktadır (Valchovski, 2016). Bu ekosistem mühendisleri bahsetmiş olduğumuz özellikleri ile orman ekosisteminin oluşumu, yapısı, işleyişi ve fonksiyonu üzerine önemli etkilere sahiptir ve bu etki göz ardı edilemeyecek kadar büyüktür (De Wandeler ve ark., 2016).

Ancak, 150 yıldan daha uzun süredir toprak solucanları ile çalışılmasına rağmen elde edilen bilgiler solucanların taksonomisi, temel özellikleri ve ekolojisinden ileriye gidememiştir ve toprak solucanları hakkında birçok şey hala gizemini korumaktadır. Günümüzde ekolojisi, taksonomisi ve dağılımı üzerine araştırmalar yapılmasına rağmen, hala toprak solucanı komüniteleri ve onların habitat üzerine olan etkileri, bitkiler ve diğer canlı grupları ile olan ilişkileri hakkında birçok bilginin eksik olduğu ve önemli bilgi eksikliklerinin hissedildiği ifade edilmektedir (Zicsi ve ark., 2011; GutiérrezLópez ve ark., 2016).

Ülkemizde orman ekosisteminde türün yetişme ortamı ile ilişkisi (Özkan, 2004a; 2004b; 2006; Gülsoy, 2006; Negiz, 2013; Karataş, 2014; Kuzugüdenli, 2014;), türün vejetasyon ve çevre ile olan ilişkisi (Özkan, 2008c; 2009; Güner, 2011a; Güner, 2011b; Şentürk, 2013; Ulusan, 2016), tür dağ1lımının çevre ile ilişkisi (Özkan, 2008a; 2008b; 2010), türün potansiyel dağılım modellemesi (Şentürk, 2010; 2012; Özkan, 2014) ve türün ekolojik verilerinin modellenmesi (Özkan, 2012; Gülsoy, 2014;) konularında uzun yıllardır çalışılmaktadır. Ancak bu çalışmalarda toprak solucanlarına gereken önem verilmediği, hedef tür olarak dikkate alınmadığı ve toprak solucanları ile ilgili herhangi bir çalışma yapılmadığı görülmüştür. Bu nedenle toprak solucanlarının orman ekosistemine olan etkileri, orman ekosisteminde vejetasyon ve çevre ile olan ilişkileri, yetişme ortamı ile olan ilişkileri, ekolojik verilerinin, yayılış alanlarının ve potansiyel yayılış alanlarının modellenmesi konularında çalışma yapılmasına ihtiyaç vardır.

Bu canlılarla çalışabilmek için, öncelikle zarar görmeden topraktan çıkarılmaları gerekir. Orman ekosistemlerinde toprak solucanlarını çıkartmada kullanılan birden fazla metot vardır. Bu metotların her biri farklı özellikte olup, etkinlikleri toprak s1caklığı, toprak nemi ve toprak porozitesinin yanı sıra solucanların genç, ergin, olgun ya da aktif oluşuna bağlı olarak değişim göstermektedir (Gutiérrez-López ve ark., 2016).

$\mathrm{Bu}$ derlemede, orman ekosistemlerinde en çok kullanılan toprak solucanı çıkartma metotlarına yer verilmiştir. 


\section{Solucan Çıkartma İşleminde Kullanılan Metotlar ve Alan Hazırlığı}

Orman ekosistemlerinde toprak solucanlarını toprak içerisinden çıkartmak için çeşitli metotlar kullanılmaktadır. Bu metotlar aktif (elle kazma ve ayıklama) ve pasif (kimyasal uyarıcılar) metotlar olmak üzere ikiye ayrılır. Aktif metotlar yoğun beden işçiliği ve iş gücü gerektiren metotlardır. Pasif metotlar ise yoğun beden işçiliği gerektirmeyen ve genellikle solucanları çeşitli yollarla uyararak topraktan dışarı çıkmasını sağlayan metotlardır. Buna göre çalışmada yer alan kazma ve elle ayırma metodu aktif metot, çeşitli kimyasallar ve elektrikle uyararak toprak solucanı çıkartma metotları ise pasif metotlardır.

Kimyasal uyarıcılar ile toprak solucanı çıkartma metotları, aktif metotlara göre daha basit ve daha az zaman alan metotlardır. Ancak kimyasal metotlar anesik türlerin açtıkları galerilerin dikey olması nedeniyle daha etkili iken, epijeik ve endojeik türlerin açtıkları galerin yatay olması nedeniyle bu türler üzerindeki etkinliği anesik türlere göre zayıftır. Ayrıca kimyasal metotların bazı durumlarda kullanılmaları sakıncalıdır. Örneğin; içme suyu kaynaklarına yakın ya da korunan alanlarda içme suyuna karışma ihtimali ya da alana zarar verme ihtimali nedeniyle kullanılmamalı, bu gibi durumlarda çevre dostu ve kimyasal olmayan uyaricılar (hardal, soğan suyu, elektrik gibi) ile solucan çıkartma işlemi gerçekleştirilmelidir.

Topraktan solucan çıkartma ve örnekleme işlemi 3 aşamada gerçekleştirilmektedir. Bunlar;

Solucan çıkartılacak alanın hazırlanması, topraktan solucanların çıkartılması ve çıkartılan solucanların teşhis edilmesi ve saklanmasıdır (Crumsey, 2014; Gutiérrez-López ve ark., 2016).

\subsection{Solucan çıkartılacak alanın hazırlanması}

Hangi metot kullanılırsa kullanılsın, önce metodun uygulanacağı alanın sınırlarının belirlenmesi gerekmektedir. Bu sınırlar çalışmanın amacına ve kapsamına göre değişiklik gösterebilir. Literatürde en çok kullanılan alan ölçüleri $25 \times 25 \mathrm{~cm}$ (Kalu ve ark., 2015; De Wandeler ve ark., 2016), 30x30 cm (Chan ve Munro, 2001), 40x40 cm (Pelosi ve ark., 2014), 50x50 cm (Khan, 2014) ve $100 \times 100 \mathrm{~cm}$ (Nxele ve ark., 2015)'dir.

Ölçü belirlendikten sonra örnekleme alanı içerisinde bulunan dökülmüş yaprak, dal parçası ve otsu bitkiler temizlenmeli, temizlenen dal par- çaları, yapraklar ve otsu bitkiler atılmadan önce içerisinde toprak solucanı olup olmadığı kontrol edilmelidir. $\mathrm{Bu}$ işlem toprak yüzeyini deforme etmeden yapılmalıdır. Toprak yüzeyinin deformasyona uğraması galerilerin dışarıya olan bağlantılarını kapatabilir. Böyle bir durumda toprak solucanları dışarıya çıkamayabilir, bu da yapacak olduğumuz çalışmanın sonucunu olumsuz olarak etkileyebilir. Bu işlemlerden sonra örnekleme alanı solucan çıkartma metodunu uygulamak için uygun hale getirilmiş olur. Yapılacak çalışmanın amacına ve alanın durumuna göre uygun olan metotlardan bir ya da bir kaçı belirlenerek uygulanabilir (Duriez ve ark., 2006; Szlavecz ve ark., 2013; Gholami ve ark., 2016; Gutiérrez-López ve ark., 2016).

\subsection{Kazma ve elle ayırma metodu}

Adında da anlaşılacağı üzere metot, toprağın kürek yardımı ile kazılması ve çıkarılan toprak içerisindeki solucanların elle seçilmesi prensibi ile çalışmaktadır.

Tekerrürlü çalışmalar ve büyük ölçekteki çalışmalar için pratik olmayan, toprağın fiziksel yapısını tahrip eden (Gutiérrez-López ve ark., 2016), yoğun iş gücü ve zaman gerektiren bir metottur (Valckx ve ark., 2011; Szlavecz ve ark., 2013). Ancak bu dezavantajına rağmen çoğu türün topraktan çıkarılmasında kullanılan en iyi metot olarak kabul edilmektedir (Weyers ve ark., 2008). Epijeik ve endojeik türlerin çıkarılmasında etkili bir metot iken anesik türlerin çıkarılmasında etkili bir metot değildir (Gutiérrez-López ve ark., 2016).

Uygulama yapılırken toprak kürek yardımı ile mümkün olduğunca tek blok halinde çıkartılır (Gholami ve ark., 2016). Çıkartılan toprak, plastik, açık renkli bir zemin üzerine dökülür ve içerisinde bulunan toprak solucanları elle seçilir (Nxele ve ark., 2015).

\subsection{Elektrikle çıkartma metodu}

Toprağın fiziksel yapısının bozulmadan, toprağı ve canlıyı tahrip etmeden toprak solucanlarının dişarı çıkmasını sağlamaktadır (Xu ve ark., 2013). Toprağın fiziksel yapısının zarar görmesini istemediğimiz, elle kazma metodu ve kimyasal metotların kullanılamayacağı alanlarda tercih edilen bir metottur. Bu metotla solucan çıkartmak için oktet aygitı adı verilen bir cihaz kullanılmaktadır (Şekil 1).

Cihazda 8 adet prop vardır ve cihaz dışarıdan bir güç kaynağına bağlı olup aldığı voltaj ve amperi alçaltıp yükseltebilme özelliğine sahiptir. Çalışma 
prensibi, proplar karşılıklı gelecek ve bir sekizgen oluşturacak şekilde toprağa saplanır. Daha sonra bir kırmızı (+) bir siyah (-) kablo ile karşılık gelecek şekilde proplara bağlanır. Cihaz aracılığı ile belirli periyotlarla amper değeri $1 \mathrm{~A}$ ve voltaj değeri $120 \mathrm{~V}$ geçmeyen sabit değerlerde elektrik ak1mı proplara gönderilir. Proplar üzerinden toprağa iletilen elektrikten etkilenen toprak solucanlarının yüzeye çıkması beklenir. Yüzeye çıkan toprak solucanları elle toplanır.

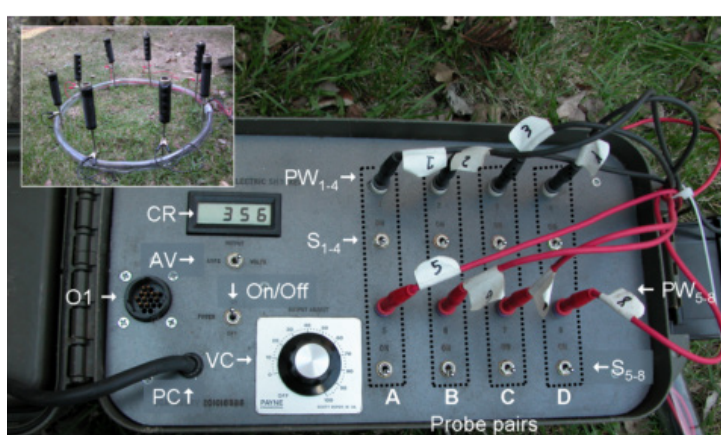

Şekil 1. Oktet aygitı

Figure 1. Octett device

Metodun verimliliği toprak nemi, toprağın elektriksel iletkenliği, toprak sicaklığı gibi toprağın fiziksel ve kimyasal özelliklerine bağlı olarak değişmektedir. Metodun verimli çalışması için 1l1man bölgelerde toprak sıcaklığ $6-10{ }^{0} \mathrm{C}$ olmalıdır (Weyers ve ark., 2008; Szlavecz, ve ark., 2013).

\subsection{Formaldehit ile çıkartma metodu}

Raw (1959) tarafından bilim dünyasına tanıtılan formaldehit (formalin) metodu en çok bilinen ve kullanılan metottur. Formaldehit, toprağın fiziksel yapısına zarar vermemekte ancak insan ve çevre sağlığı açısından riskli olup, son derece toksik ve kanserojenik özelliklere sahiptir (Bartlett ve ark., 2006). İçme suyu kaynaklarının yakınlarında ve koruma alanlarında kullanılması uygun değildir.

Uygulama için ilk olarak kullanılacak miktarda (min. 3 1) \%0,5 formaldehit solüsyonu hazırlanır. Solucanları topraktan dışarı çıkartmak için \%0,5 formaldehit solüsyonunun önce yarısı solucan çıkartılacak alana sprey şeklinde ya da dökülerek uygulanır. Yaklaşık 5 dakika beklendikten sonra kalan yarısı da uygulanarak toprak solucanlarının çıkması beklenilir. Çıkan toprak solucanları elle toplanır (Steffen ve ark., 2013; Gutiérrez-López ve ark., 2016). Canlı ve çevre sağlığı açısından zararlı olmasına rağmen, formaldehit solüsyonu ile toprak solucanı çıkartma metodu kazma ve elle ayırma metoduna göre daha hızlı ve avantajlı bir metottur
(Steffen ve ark., 2013).

\subsection{Soğan ekstraktı ile çıkartma metodu}

Formaldehit metoduna alternatif olarak kullanılabilecek, hem düşük maliyetli, hem de toksik ve kanserojenik olmayan çevre dostu bir metottur. Canlılara ve çevreye herhangi bir yan etkisi yoktur. Karışım, uygulamadan en az 1 saat önce hazırlanmalıdır ve hazırlanırken beyaz soğan kullanılmalıdır. Karışım hazırlanırken 1 litre su içerisine $175 \mathrm{~g}$ soğan ekstraktı ilave edilir ve miktarı uygulanacak alanın büyüklügüne göre artırılabilir. Hazırlanan karışımın bir kısmı solucan çıkartılacak olan alana sprey şeklinde ya da dökülerek uygulanır; bir süre bekledikten sonra kalan kısmı da uygulanarak solucanların yüzeye çıkması beklenir. Çıkan toprak solucanlar1 elle toplanır (Steffen ve ark., 2013).

\subsection{Allylisothiocyanate(aItc)ileçıkartmametodu}

Allyl isothiocyanate (AITC), hardal içerisindeki enzimatik bir parçalanma sonucunda üretilen aktif bir alkaloittir. Turpgiller (Brassicaceae) familyasına ait birçok sebzede doğal olarak bulunur. Kullanılacak olan çözelti taze hazırlanmalı ve hazırlandıktan sonra etkinliğini kaybetmemesi için 4 saat içerisinde kullanılmalıdır. Çözeltiyi hazırlamak için önce $5 \mathrm{~g} / 1$ AITC, \%70 etanol içerisinde çözülür ve bu çözelti $0,1 \mathrm{~g} / 1$ olacak şekilde su ile seyreltilir. Hazırlanan çözeltinin yarısı solucan çıkartılacak alan üzerine dökülerek ya da püskürtülerek uygulanır, 5 dakika beklenir ve kalan yarısı da alana uygulanarak toprak solucanlarının çıkması beklenir. Toprak yüzeyine çıkan toprak solucanları elle toplanır (Zaborski, 2003; Gutiérrez-López ve ark., 2016).

\subsection{Potasyum permanganat ile çıkartma metodu}

İlk kez Evans ve Guild (1974) tarafından kullanılmıştır. Formaldehit ile çıkartma metoduna göre etkinliği daha azdır. Metot, diğer kimyasal metotlara benzer şekilde hazırlanmakta ve uygulanmaktadır. Potasyum permanganat ile hazırlanan çözeltinin bir kısmı toprak solucanı çıkartılacak alana uygulanır bir süre (yaklaşık 5 dakika) beklendikten sonra kalan kısmı da uygulanarak solucanların çıkması beklenir ve çıkan toprak solucanları elle toplanır (Paoletti, 1999; Gutiérrez-López ve ark., 2016).

\subsection{Hardal ile çıkartma metodu}

Çevreye ve canlılara zarar vermeyen çevre dostu bir solucan çıkartma metodudur (Eisenhauer ve ark., 2008). Formaldehit metoduna alternatif bir metot olmasinın yanında formaldehit metodundan daha etkilidir (Zaborski, 2003). 
Hardal metodu, formalin ve potasyum permanganat gibi solucanları öldürmez ve fitotoksik etki göstermez (Valckx ve ark., 2011). Ayrıca formalin gibi toksik ve kanserojen değildir. Metot için toz hardal (hardal unu, hardal tozu) ya da ticari olarak satılan hardallar kullanılabilmektedir (Gunn, 1992). Hardal karışımı hazırlamak için, $106 \mathrm{~g} / 1$ hardal unu \%5 asetik asit içerisine koyulur ve 1 gün bekletilir. Ertesi gün bu süspansiyon içerisinden alınan $15 \mathrm{ml}$ karışım 1 litre suya eklenerek hardal süspansiyonu elde edilir.

Eğer ticari hardal ile bu süspansiyon hazırlanacak ise $150 \mathrm{~g}$ ticari hardal 5 litre su içerisine eklenir ve 1 gün bekletildikten sonra kullanılır. Ancak, burada ticari hardalın üretim tarihi oldukça önemli olup satın alındığ 1 tarihe en yakın olanlar ve aynı partide üretilenler tercih edilmelidir (Pelosi ve ark., 2014).

Uygulama ise, solucan çıkartılmak istenen alana elde edilen süspansiyonun önce yarısı dökülür bir süre (yaklaşık 5 dakika) beklendikten sonra da kalan yarısının uygulanması ile gerçekleştirilir. Solucanların yüzeye çıkması beklenir. Çıkan toprak solucanlar1 elle toplanır (Chan ve Munro, 2001).

\subsection{Tuzakla yakalama metodu}

Büyüklüğü çalışmaya göre değişen cam ya da plastik kavanozlar toprağa gömülerek toprak solucanlarının içine düşmesi için tuzak kurulur. Bunun için toprak, kavanoz yerleştirilecek şekilde kazılır ve kavanoz, ağız kısmı toprak yüzeyi ile aynı seviyede olacak şekilde toprak içerisine yerleştirilir. Geceleri beslenmek ya da çiftleşmek için toprak içerisindeki galerilerden toprak yüzeyine çıkan ve toprak yüzeyinde gezinen toprak solucanlarının kavanoz içerisine düşmesi beklenir. Kavanozların içerisine bir miktar formaldehit ya da pikrik asit solüsyonu konularak kavanoz içerisine düşen solucanların ölmesi sağlanabilir (Misırlığlu, 2011).

Toprak solucanı yakalamak için derlemede değinilen metotlar dişında kalan (bulaşık deterjanı, taşların ve devrilmiş kütüklerin altından toplama, toprak 1sıtma) başka metotlar da vardır (Čoja ve ark., 2008; Nxele ve ark., 2015).

Derlemede yer verilen metotlar, literatürde bulunan ve solucan çıkartma çalışmalarında en çok tercih edilen metotlardır. Bu metotların her biri ayrı ayrı kullanıldığı gibi birkaç metot birleştirilerek de kullanılabilmektedir.

Metot uygulanıp solucanlar topraktan çıkarıldıktan sonra taksonomik çalışmalar için yapısı bozulmadan saklanmalıdır. Bu kısım tüm metotlarda kullanıldığı için tek bir başlık altında verilmesi tercih edilmiştir.

\section{3. Çıkartılan Solucanları Saklama Koşulları}

Çıkartılan solucanların saklanmasında plastik ya da cam kaplar kullanılmaktadır. Ancak solucanlar saklama kaplarına alındıktan sonra periyodik olarak bozulma ve yumuşama gibi durumlara karş1 kontrol edilmelidir. Dokularda meydana gelecek bozulma ve yumuşama istenmeyen bir durumdur. Çünkü solucanlar üzerinde yapılacak olan taksonomik çalışmaları zorlaştırır. Bu nedenle solucanların uzun süre saklanması için aşağıda belirtilen adımlar uygulanır.

- Solucanlar \%5-10 etil alkole atılır ve hareketsiz kalıncaya kadar bekletilir.

- Sonra \%4 formaldehit içerisinde 1-2 gün bekletilir.

- Son olarak \%70-80 etil alkol içerisine alınır ve saklanır.

Son aşamada alkol renginde değişmeler olabilir. $\mathrm{Bu}$ nedenle, alkol renginde değişme görülmeyene kadar yeni hazırlanmış \%70-80 etil alkol ile haftalık periyotlarla değiştirilir (Mısırlığlu, 2011).

\section{Sonuçlar ve Öneriler}

Sonuç olarak toprak solucanları, özellikle toprak ve orman ekosistemi için oldukça önemli canlılardır. Orman ekolojisinde farklı konularda vejetasyon-çevre ilişkileri, tür-habitat dağılım modellemeleri, türlerin birbirleri ile olan ilişkileri ve türün potansiyel dağılım modellemeleri konusunda birçok çalışma yapılmasına rağmen, hedef tür ya da toplumlar olarak toprak solucanlarının dikkate alınmadığı görülmüştür. Bu nedenle ülkemizde bu canlılarla ilgili yeterince çalışma yapılmadığı kanaatine varılmıştır.

Toprak solucanlarının taksonomisi ve genel ekolojileri hakkında temel ya da genel bilgilere sahip olsak ta, bu mükemmel canlılar hakkında daha çok bilgi edinebilmemiz ve ekosistem ile ilişkisi ve işleyişi üzerine olan etkilerini anlayabilmemiz için toprak solucanlarının orman ekosisteminde vejetasyonçevre ile olan ilişkileri, tür-habitat dağılım modellemeleri, türlerin birbirleri ile olan ilişkileri konularında toprak solucanları ya da toplumları hedef tür alınarak çalışmalar yapılması gerekmektedir. Bu derleme, özellikle orman ekosisteminde gelecekte yapılacak olan toprak solucanı çalışmalarına 1 şık tutmak ve yardımcı olmak amacıyla hazırlanmıştır. 


\section{Kaynaklar}

Bartlett, M. D., Harris, J. A., James, I. T., Ritz, K., 2006. Inefficiency of mustard extraction technique for assessing size and structure of earthworm communities in UK pasture. Soil Biology and Biochemistry 38(9): 2990-2992.

Birkas, M., Bottlik, L., Stingli, A., Gyuricza, C., Jolánkai, M., 2010. Effect of soil physical state on the earthworms in hungary. Applied and Environmental Soil Science 2010: 1-7.

Chan, K.Y., Munro, K., 2001. Evaluating mustard extracts for earthworm sampling. Pedobiologia 45(3): 272-278.

Čoja, T., Zehetner, K., Bruckner, A., Watzinger, A., Meyer, E., 2008. Efficacy and side effects of five sampling methods for soil earthworms (Annelida, Lumbricidae). Ecotoxicology and Environmental Safety 71(2): 552-565.

Crumsey, J. M., 2014. Exotic Earthworm Communities as Drivers of Soil Carbon Dynamics in Northern Temperate Forests, The University of Michigan, Ecology and Evolutionary Biology, 164 p., Ann Arbor.

Çakır, M., Makineci, E., 2011. Toprak faunası: Sınıflandırılması ve besin ağındaki yeri. İstanbul Üniversitesi Orman Fakültesi Dergisi 61(2): 139-152.

De Wandeler, H., Sousa-Silva, R., Ampoorter, R. E., Bruelheide, H., Carnol, M., Dawud, S. M., Dănilă, G., Finer, L., Hättenschwiler, S., Hermy, M., 2016. Drivers of earthworm incidence and abundance across european forests. Soil Biology and Biochemistry 99: 167-178.

Duriez, O., Ferrand, Y., Binet, F., 2006. An adapted method for sampling earthworms at night in wildlife studies. Journal of Wildlife Management 70(3): 852-858.

Eisenhauer, N., Straube, D., Scheu, S., 2008. Efficiency of two widespread non-destructive extraction methods under dry soil conditions for different ecological earthworm groups. European Journal of Soil Biology 44(1): 141-145.

FİBL. 2017. Earthworms-architects of fertile soils. https://shop.fibl.org $>1629$-earthworms (Ziyaret tarihi: 24.02.2017).

Gholami, S., Sayad, E., Gebbers, R., Schirrmann, M., Joschko, M., Timmer, J., 2016. Spatial analysis of riparian forest soil macrofauna and its relation to abiotic soil properties. Pedobiologia 59(1): 27-36.

Gulsoy, S., Suel, H., Celik, H., Ozdemir, S., Ozkan, K., 2014. Modeling site productivity of Anatolian black pine stands in response to site factors in Buldan district, Turkey. Pakistan Journal of Botany 46(1): 213-220.

Gunn, A., 1992. The use of mustard to estimate earthworm populations. Pedobiologia 36(2): 65-67.

Gutiérrez-López, M., Moreno, G., Trigo, D., Juárez, E., Jesús J. B., Cosín, D. J. D., 2016. The efficiency of earthworm extraction methods is determined by species and soil properties in the Mediterranean communities of Central-Western Spain. European Journal of Soil Biology 73: 59-68.

Gülsoy, S., 2006. Sütçüler (Isparta) yöresinde karaçamın (Pinus nigra arn. subsp. pallasiana (Lamb.) Holmboe) boy gelişimi ile bazı yetişme ortamı özellikleri arasındaki ilişkiler. Süleyman Demirel Üniversitesi, Fen Bilimleri Enstitüsü, Orman Mühendisliği Anabilim Dalı, 93 s., Isparta.

Güner, Ş. T., Özkan, K., Yücel E., 2011a. Sarıçam ormanlarının verimliliği ile vejetasyon ve tür çeşitliliği arasındaki ilişkiler, Süleyman Demirel Üniversitesi Orman Fakültesi Dergisi, 12(1): 1-6.

Güner,Ş.T.,Özkan,K.,Çömez,A., 2011b.Key factorsinthe site selection of Rosa canina (L.)-aplying the generalized additive model. Polish Journal of Ecology 59(3): 475-482.

Jouquet, P., Bottinelli, N., Podwojewski, P., Hallaire, V., Duc, T. T., 2008. Chemical and physical properties of earthworm casts as compared to bulk soil under a range of different land-use systems in Vietnam. Geoderma 146(1): 231-238.

Kalu, S., Koirala, M., Khadaka, U. R., 2015. Earthworm population in relation to different land use and soil characteristics. Journal of Ecology and The Natural Environment 7(5): 124-131.

Karataş, R., 2014. Eskişehir, Afyonkarahisar ve Ankara illerindeki sedir (Cedrus libani A. Rich.) ağaçlandırmalarının gelişimi ile bazı yetişme ortamı özellikleri arasındaki ilişkiler. Süleyman Demirel Üniversitesi, Fen Bilimleri Enstitüsü, Orman Mühendisliği Anabilim Dal1, 103 s., Isparta.

Khan, A. A., 2014. Earthworms-the soil ecosystem engineers. 34. Pakistan Congress of Zoology, Bahauddın Zakariya University, Multan, 25-27 February 2014,pp. 31-47.

Kuzugüdenli, E., 2014. Batı Akdeniz bölgesinde boylu ardıçın (Juniperus excelsa Bieb.) boy gelişimi ile bazı yetişme ortamı faktörleri arasındaki ilişkiler. Süleyman Demirel Üniversitesi, Fen Bilimleri Enstitüsü, Orman Mühendisliği Anabilim Dalı, 275 s., Isparta.

Mısırlığlu, İ. M., 2001. Doğanın gönüllü bahçıvanları. Bilim ve Teknik Dergisi Kasım Sayıs1: 78-80.

Misırlığlu, İ. M., 2011. Toprak Solucanlar1 Ekolojileri ve Türkiye Türleri. Nobel Yayın Dağıtım, Ankara.

Misırlığlu, İ. M., 2017. Diversity of earthworm (clitellata, annelida) species in asian and european part of Turkey. Kahramanmaraş Sütçü İmam Üniversitesi Journal of Natural Science 20(2): 115-119.

Negiz,M.G.,2013.Gölhisar(Burdur)yöresindeodunsutür çeşitliliği ile yetişme ortamı özellikleri arasındaki ilişkiler. Süleyman Demirel Üniversitesi, Fen Bilimleri Enstitüsü, Orman Mühendisliği Anabilim Dal1, 200 s., Isparta. 
Nxele, T., Lamani, S., Measey, G. J., Armstrong, A., Plisko, J. D., Willows-Munro, S., Janion-Scheepers, C., Wilson, J., 2015. Studying earthworms (Annelida: Oligochaeta) in south Africa. African Invertebrates 56(3): 779-806.

Ozkan, K,. Bilir, N., 2008b. Influence of soil and topographical characteristics on spatial distribution of wild rosa (Rosa canina L.) and its indicator species in Beysehir watershed, Mediterrian region, Turkey. The Malaysian Forester Journal 71(Special issue): 87-96.

Ozkan, K., Berger, U., 2014. Predicting the potential distribution of plant diversity in the Yukarigökdere forest district of the mediterranean region. Polish Journal of Ecology 62(3): 441-454.

Ozkan, K., Çelik, S., 2008a. Spatial distribution of $J u$ niperus exelsa Bieb. in relation to its site factors. The Malaysian Forester Journal 71(Special issue): 1-7.

Ozkan, K., Gulsoy, S., Mert, A., Ozturk, M., Muys, B. 2010. Plant distribution-altitude and landform relationships in karstic sinkholes of Mediterranean region of Turkey. Journal of Environmental Biology 31(1-2): 51-60

Ozkan, K., Senol, H., Gulsoy, S., Mert, A., Suel, H., Eser, Y., 2009. Vegetation-environment relationships in mediterranean mountain forests on limeless bedrocks of southern anatolia, Turkey. Journal of Environmental Engineering and Landscape Management 17(3): 154-163.

Ozkan, K., Suel, H., 2008c. Endemic plant species in a karstic canyon (Mediterranean Region, Turkey): relation to relief and vegetation diversity. Polish Journal of Ecology 56(4): 709-715.

Özkan, K., 2004a. Prof. Dr. Bekir Sitk1 EVCIMEN sedir koruma ormanı'nda toros sedir'inin (Cedrus libani A. Rich) gelişimi ile yetişme ortamı faktörleri arasındaki ilişkiler. Anadolu Üniversitesi Bilim ve Teknoloji Dergisi 5(2): 327-332.

Özkan, K., 2004b. Beyşehir gölü havzası'nda Anadolu karaçamının (Pinus nigra Arnold) yayıllışı ile fizyografik yetişme ortamı faktörleri arasındaki ilişkiler. Süleyman Demirel Üniversitesi Orman Fakültesi Dergisi 2(A): 30-47.

Özkan, K., 2006. Beyşehir gölü havzası Çarıksaraylar yetişme ortamı yöreler grubunda fizyografik yetişme ortamı faktörleri ile ağaç ve çalı tür çeşitliliği arasındaki ilişkiler analizi. Anadolu Üniversitesi Bilim ve Teknoloji Dergisi 7(1): 157-166.

Özkan, K., 2012. Sinıflandırma ve regresyon ağacı tekniği (SRAT) ile ekolojik verinin modellenmesi. Süleyman Demirel Üniversitesi Orman Fakültesi Dergisi 13(1): 1-4.

Paoletti, M. G., 1999. The role of earthworms for assessment of sustainability and as bioindicators. Agriculture, Ecosystems and Environment 74: 137-155.
Pelosi, C., Chiron, F., Dubs, F., Hedde, M., Ponge, J. F., Salmon, S., Cluzeau, D., Nélieu, S., 2014. A new method to measure allyl isothiocyanate (AITC) concentrations in mustard-comparison of AITC and commercial mustard solutions as earthworm extractants. Applied Soil Ecology 80: 1-5.

Raw, F., 1959. Estimating earthworms populations by using formalin. Nature 184: 1661-1662.

Sentürk, O., Ulusan, M. D., Eser, Y., Senol, A., Ozkan, K., 2013. Investigation of relationships between vegetation and environmental factors in the Cariksaraylar district of the sultan mountains. GeoMed 2013 The 3rd International Geography Symposium, Antalya, 10-13 June 2013, pp. 597-607.

Staddon, P. L., Ostle, N., Fitter, A. H., 2003. Earthworm extraction by electroshocking does not affect canopy $\mathrm{CO}_{2}$ exchange, root respiration, mycorrhizal fungal abundance or mycorrhizal fungal vitality. Soil Biology and Biochemistry 35(3): 421-426.

Steffen, G. P. K., Antoniolli, Z. I., Steffen, R. B., Jacques, R. J. S., Dos Santos, M. L., 2013. Earthworm extraction with onion solution. Applied Soil Ecology 69: 28-31.

Szlavecz, K., Pitz, S. L., Bernard, M. J., Xia, L., O’Neill, J. P., Chang, C. H., McCormick, M. K., Whigham, D. F., 2013. Manipulating earthworm abundance using electroshocking in deciduous forests. Pedobiologia 56(1): 33-40.

Şentürk, Ö., 2012. Sütçüler yöresinde asli orman ağac1 türlerinin potansiyel yayılış alanlarının modellenmesi. Süleyman Demirel Üniversitesi, Fen Bilimleri Enstitüsü, Orman Mühendisliği Anabilim Dalı, 196 s., Isparta.

Şentürk, Ö., Mert, A., Gülsoy, S., Özkan, K., Özdemir, İ., 2010. Sipahiler - Hacıaliler mevkisinde karaçam ve kızılçam türlerinin potansiyel yayılışlarının modellenmesi. Isparta İli Değerleri Ve Değer Yaratma Potansiyeli Sempozyumlar1, Isparta 26 Nisan- 3 Mayıs 2010, s. 917-926.

Taşdelen, S., 2012. Jeolojik Zaman Çizelgesi. SDUGEO 3(1):26-35.

Ulusan, M. D., 2016. Akdeniz bölgesi, ovacık dağı yöresi'nde odunsu vejetasyonun dağılımı ile yetişme ortamı özellikleri arasındaki ilişkilerin ordinasyon metotları ile araştırılması. Süleyman Demirel Üniversitesi, Fen Bilimleri Enstitüsü, Orman Mühendisliği Anabilim Dalı, 168 s., Isparta.

Valchovski, H., 2016. Influence of soil organic matter content on abundance and biomass of earthworm (Oligochaeta: Lumbricidae) populations. Ecologia Balkanica 8(1): 107-110.

Valckx, J., Govers, G., Hermy, M., Muys, B., 2011. Optimizing earthworm sampling in ecosystems. In: Ayten KARACA (Ed), Biology of Earthworms, Springer Verlag, Germany, pp. 19-38. 
Weyers, S., Schomberg, H., Hendrix, P., Spokas, K., Endale, D., 2008. Construction of an electrical device for sampling earthworm populations in the field. Applied Engineering in Agriculture 24(3): 391-397.

Xu, S., Johnson-Maynard, J., Prather, T., 2013. Earthworm density and biomass in relation to plant diversity and soil properties in a palouse prairie remnant. Applied Soil Ecology 72: 119-127.
Zaborski, E. R., 2003. Allyl isothiocyanate: an alternative chemical expellant for sampling earthworms. Applied Soil Ecology 22(1): 87-95.

Zicsi, A., Szlavecz, K., Csuzdi, C., 2011. Leaf litter acceptance and cast deposition by peregrine and endemic european lumbricids (Oligochaeta: Lumbricidae). Pedobiologia 54: 145-152. 